\title{
Collaborative Capability of Teams in Network Organizations
}

\author{
Sebastian Ulbrich ${ }^{1}$, Heide Troitzsch ${ }^{1}$, Fred van den Anker ${ }^{1}$, Adrian Plüss ${ }^{2}$, \\ and Charles Huber ${ }^{2}$ \\ ${ }^{1}$ UAS Northwestern Switzerland, School of Applied Psychology, \\ Riggenbachstrasse 16, 4600 Olten, Switzerland \\ ${ }^{2}$ UAS Northwestern Switzerland, School of Engineering, Promenade 26, \\ 5200 Brugg, Switzerland \\ \{Sebastian.Ulbrich, Heide.Troitzsch, Fred.vandenAnker, \\ Adrian.Pluess, Charles.Huber @ fhnw. ch
}

\begin{abstract}
In this paper, we present a study on collaborative capability of teams in three network organizations in Austria and Switzerland. So far, collaborative capability was mostly conceptualized on organizational or individual level as a set of attributes that actors employ to collaborate successfully. We found that this view of collaborative capability has to be enlarged. Collaborative capability of teams is characterized by at least two components: an attribute-based perspective that focuses on capabilities of single actors or organizations, and a perspective on group dynamics, that describes how teams develop collaborative capability. We discuss our findings with regard to the different organizational settings of the networks analyzed and the current literature on collaborative capability and network organizations.
\end{abstract}

Keywords: Collaborative capability, network organizations, group dynamics.

\section{Introduction}

In recent years, collaborative capability was found to be a major contributor to firms' competitive advantage [1,2]. Scholarly interest in the subject co-evolved with organizations' interest in implementing more flexible forms of collaboration both within and beyond organizational boundaries. Finally, network organizations as promising new forms of collaboration emerged $[3,4,5]$.

Miles and Snow [3] point out, that these new dynamic forms of inter-firm collaboration are able to "[...] accommodate a vast amount of complexity while maximizing specialized competence [...]" (p.69). As flexible and voluntary forms of collaboration become important themes in business, the question how actors establish, develop, and maintain the ability to collaborate successfully is crucial. Today, there are many conceptualizations of collaborative capability on organizational and individual level, but organizational research is still lacking a detailed description of how managers translate collaborative capability into the social praxis of inter-firm collaboration [2]. Furthermore, there is still some necessity for research with regard to collaborative capability at the team level [6]. Thus, with this research we tackle the problem how teams in network organizations establish, develop, and maintain collaborative capability. 
We studied the emergence and maintenance of collaborative capability of teams in three diverse network organizations in Austria and Switzerland focusing on attributes of single actors as well as the organizational framework and work requirements. Employing a process-based view on collaboration our focus lies on the dynamics of collaboration at an early stage of project work in network organizations.

\section{Collaborative Capability - A Multifaceted Concept}

A large body of research has grown around collaborative capability and related concepts. In an overview, Blomqvist and Levy [7] identify trust, communication, and commitment, as crucial factors for collaborative capability. Trust is the basis for effective communication among network partners, thus facilitating knowledge creation and innovation in networks [7]. Building relationships which are based on mutual trust seems to be one of the most important tasks in inter-firm collaboration $[1,8,9$, $10,11,12]$.

Vartiainen [13] found a strong emphasis on collective competences in a study on virtual organizations. Characteristics of the collective competences were clarity with regard to goals and operations, the establishment of a "bird's eye view" on the project, mutual trust, "l'esprit d'équipe" (team spirit), and commitment. On the level of actions, open and frequent interaction as well as working process compliance turned out to be important in virtual organizations. For Heimeriks and Schreiner [10], mutual trust is a crucial characteristic of high performance alliances. It comprises actors' willingness to act in benevolence to the relationship and not against it. Trust builds around partner's credibility, the mutual goodwill to act in benefit of the relationship, and a general predictability of the behavior of others.

Cullen et al. [9] describe the "soft side" of successful strategic alliance management to be closely related to the concepts of trust and commitment. According to the authors, trust in alliances is rooted in a rational and emotional base. Partners trust each other to meet their obligations and make promised contribution but also believe that an alliance partner will behave with goodwill towards the alliance and single partners. Commitment concerns the willingness of the partners to continue the relationship. It can be calculative or attitudinal. If partners are willing to care for the alliance, they will more likely allocate resources to the alliance [9]. Of course this kind of "caring" for a professional relationship is closely related to economic gains. As Sivadas and Dwyer [12] pointed out, partners enter into a strategic alliance to maximize their own gains. If gains are made at the expense of others, and are perceived as deceit, the relationship will be negatively affected. Effective communication can help solve the problem if an initial lack of trust is experienced.

We argue that the three main components of collaborative capability - trust, communication, and commitment - are closely interrelated and dependent on the economic success of the collaborative process. For example, Mohr and Spekman [14] found better communication quality and information sharing in successful partnerships. According to Blau [15], trust develops slowly through experiencing immediate returns from collaboration. In a longitudinal study on interfirm networks, Lorenzoni and Lipparini [16] found, an increase in trust and familiarity among partners reduced transaction and coordination costs. 
To disentangle the complexity of the concept, but add yet another line of thought, a process-based approach to collaborative capability may be helpful. Actors, be it organizations or individuals, learn from collaboration experiences, thus having the chance to adapt their behavior in future collaborations accordingly. In consent with this line of argument, Kale et al. [17] define alliance capability as the firm's ability to learn from alliance experience and successfully apply insights to future alliances. From a perspective on organizational learning, this capability develops through recombining and integrating knowledge acquired from past actions. Effective actions will more likely be repeated in the future. As Anand and Khanna [18] pointed out that one of the most important factors of alliance success is previous experience with alliances. Kale et al. [17] argue that alliance experience helps firms to develop a relational capability.

From the literature on collaborative capability it is not clear whether capabilities that are beneficial to collaboration, for example to be able to communicate in a way that more likely builds trust relationships, are cause or consequence of successful collaboration. Moreover, if we consider a given set of organizational actors who collaborate for the first time, even if they are trustworthy, committed to the team, and communicate in an open manner - many potential pitfalls of collaboration may influence the process. Because collaboration success depends on the outcome of specific situations and organizational settings in which actors have to meet many challenges to fulfil work requirements, we propose to enlarge the perspective on collaborative capability.

\subsection{A Process-Based Approach to Collaborative Capability}

Many attribute-based concepts approach collaborative capability in hindsight, after it had been established among partners. However, there is empirical evidence that this perspective is somewhat skewed due to structural and historical self-selection effects. For example, in the field of Science and Technologies Studies it was found, that researchers tend to collaborate within their own groups $[19,20]$. Furthermore, researchers' readiness for transdisciplinary collaboration in science tends to be higher among those who share a history of previous collaboration [21]. This historical perspective on collaboration unfolds two possible mechanisms. Firstly, actors with a history of collaboration seem to be more prone to collaborate with others in general. Secondly, actors tend to more likely choose those alters to engage in new projects with whom they already have collaborated successfully in the past. With regard to collaborative capability, these mechanisms support the argument that once a team has achieved to accomplish its goals through collaborating, actors are more likely to repeatedly collaborate in same or similar constellations in the future.

A positive outcome of collaboration feeds back as a potential input, thus strengthening a given relationship. We suggest that it is for this particular structuring of collaboration that both attributes of single actors and social dynamics are adjusted. Social dynamics of collaboration overlay individual attributes, such as engendering trust, mutual adjusting individual styles of communication, committing to subtasks, and coordinating activities. Each interaction episode adds to the shared history of collaboration. Following Dosi, Nelson and Winter [22], we argue that capability fills the gap 
between intention and outcome of activities, so it is important for actors who work together to reach a collective state in which tasks at hand can be effectively dealt with. In this study, we explored how actors establish collaborative capability and how it is put to the test by critical incidents that occurred in the process of working together in network projects.

\section{Empirical Findings}

Following an exploratory case study approach, we studied team collaboration in three network organizations in Austria and Switzerland by means of semi-structured interviews with executives of partnering firms as well as network managers. Table 1 gives an overview of the three network organizations. The inter-firm networks varied in size and industry sector, as well as in network typology $[6,23]$. According to Sydow et al. [23], network organizations can be distinguished by their general purpose which can be product or process innovation (explorative type) or combining compatible resources in order to increase revenue, for example by reducing production costs or increasing market share (exploitative type) [24].

All three network organizations were set up to increase competitive advantage of their members but varied with regard to the means of how to achieve this. Whereas KC's main objective was to facilitate product and process innovation, thus initiating explorative projects, VB and SMT both aimed at reducing costs and optimize business processes, thus following an exploitative strategy. Whereas $\mathrm{KC}$ facilitated R\&D projects with changing network partners, VB and SMT partners tended to collaborate with one another repeatedly. The latter strategy resulted in more cohesion and stability over time.

Table 1. Characteristics of participating network organizations

\begin{tabular}{llll}
\hline Network organization & KC & VB & SMT \\
\hline Industry & Plastics & Construction & Metalworking \\
Number of network partners & 400 & 60 & 7 \\
Competitors in the network & Yes & Yes & No \\
Geographic propinquity & Yes & Yes & Yes \\
Cohesion of network & Low & Medium & High \\
Variability of relationships & Dynamic & Stable & Stable \\
Organizational design & Heterarchic & Hierarchic & Heterarchic \\
Main objective & Exploration & Exploitation & Exploitation \\
\hline
\end{tabular}

\subsection{Partner Selection}

On an organizational level, partner selection is an important prerequisite of successful collaboration, thus influencing the establishment of collaboration capability right from the start. Sivadas \& Dwyer [12] suggest that complementary competences of partners will be beneficiary whereas competition among partners should be largely 
ruled out. In network organizations, direct competition acted detrimental to the establishment of collaborative capability, since network partners sought to increase their competitive advantage and to remain independent at the same time. We found that partners who shared economic interests with regard to the same technology, markets, or products, and pursued similar strategic goals would rather not collaborate.

Framing important factors for alliance capability and collaboration quality, Heimeriks and Schreiner [10] emphasize that compatibility and similarity of partners facilitate the successful combination of complementary assets. Combining resources is root to competitive advantage of collaborating firms. According to Lambe et al. [25], successful alliances manage their complementary resources and rather not build on competitive resources.

To identify a matching partner, knowledge about technological competences and market activities is required. Partner selection was found to be a crucial prerequisite for successful collaboration, especially with regard to competition and complementary technologies and knowledge. Network partners were selected because their core competences fit the requirements of the task. Firstly, this step required knowledge about the competences necessary to fulfil the task. Secondly, actors who initiated projects had to get to know other companies, in order to target them as potential partners.

Our results illustrate that this first step of partner selection was merely based on individual attributes of partners, such as technological specialties or expertise needed for the task at hand. Partner selection emphasizes the economic factors of collaboration. Here, network management was supportive in providing information about potential partners. In addition, network management actively brokered contacts between firms. Once potential partners got to know each other and initiated collaboration, network management restricted its supportive role to monitoring the process. Network managers intervened only if they were requested to do so by the partners, for example in case of conflicts. Neutrality of network management was stressed be an important requirement for successful collaboration in all three network organizations. Whereas actors' attributes such as expertise were crucial for partner selection, collaborative capability developed in the process.

\subsection{Impact of Critical Incidents on Collaborative Capability of Teams}

Table 2 presents some example episodes that were reported to us as critical at initial stages of collaboration. In early project phases initial trust in network partners and confidence in collaboration sucesss needed to be established. This required the negotiation of shared goals, as well as an open discussion of individual interests and expectations. To build trust in project teams, open discussion and presentation of expertise was crucial. Once this first step of knowledge sharing was achieved, confidence in collaboration success rose and influenced the commitment of the partners. The same effect was observed with external feedback on preliminary project results which influenced partners' collaborative capability positively. Thus, we found that initial trust has to be backed up by behavioral evidence for partners' willingness to collaborate, the quality of the contributions, and reciprocated investments. 
Table 2. Influence of critical incidents on collaborative capabiliy

\begin{tabular}{|c|c|c|c|}
\hline Network & Incident & Outcome & Mechanisms \\
\hline $\mathrm{KC}$ & $\begin{array}{l}\text { Kick off workshop at } \\
\text { distrusted network } \\
\text { partner }\end{array}$ & $\begin{array}{l}\text { Presentation and open } \\
\text { discussion of products and } \\
\text { processes has lead to } \\
\text { intensive knowledge } \\
\text { sharing and joint problem } \\
\text { solving }\end{array}$ & $\begin{array}{l}\text { communication, trust, } \\
\text { expertise, } \\
\text { commitment }\end{array}$ \\
\hline KC & $\begin{array}{l}\text { Firms leave project due } \\
\text { to differences of } \\
\text { objectives and } \\
\text { uncertainty of project } \\
\text { outcome }\end{array}$ & $\begin{array}{l}\text { Firms negotiate project } \\
\text { goals, uncertainty is } \\
\text { reduced by clarifying } \\
\text { individual interests and } \\
\text { expectations }\end{array}$ & $\begin{array}{l}\text { communication, } \\
\text { confidence }\end{array}$ \\
\hline $\mathrm{KC}$ & $\begin{array}{l}\text { Positive feedback on } \\
\text { preliminary project } \\
\text { results }\end{array}$ & $\begin{array}{l}\text { Network partners increase } \\
\text { investment in project. } \\
\text { Uncertainty is reduced }\end{array}$ & $\begin{array}{l}\text { Resource allocation, } \\
\text { commitment }\end{array}$ \\
\hline VB & $\begin{array}{l}\text { Quick wins in low risk } \\
\text { projects }\end{array}$ & $\begin{array}{l}\text { Firms learn to build } \\
\text { confidence in } \\
\text { collaboration }\end{array}$ & $\begin{array}{l}\text { confidence, } \\
\text { trust } \\
\text { cohesion }\end{array}$ \\
\hline SMT & $\begin{array}{l}\text { Firms simulate business } \\
\text { collaboration, free } \\
\text { riders leave the network } \\
\text { when asked to } \\
\text { contribute }\end{array}$ & $\begin{array}{l}\text { Remaining executives } \\
\text { encourage each other to } \\
\text { continue and initiate } \\
\text { successful project. Other } \\
\text { firms join the network }\end{array}$ & $\begin{array}{l}\text { resource allocation, } \\
\text { reciprocity, } \\
\text { confidence, cohesion }\end{array}$ \\
\hline
\end{tabular}

\section{Concluding Remarks}

Collaborative capability in network organizations is established as a mixture of the uncertain and the assertive somewhere between future promises of and past experiences with collaboration. Where partners were able to create an atmosphere of confidence in collaboration, which was assured by the perceived quality of single contributions, collaborative capability was built. In two of the three network organizations under study firms engaged in long-term relationships. $\mathrm{KC}$ as a project network [6], brought independent partners together for short range $R \& D$ projects. This is important to note, when discussing our findings. In KC collaborative capability had to be built faster, thus relying heavily on early assurance of success. Early success increased partners' investments on the one hand but was measured by initial investments on the other. The more partners committed to the project before a promising outcome was assured, it was more likely that commitment would be reciprocated.

Individual attributes of the organizations moderated the process from the start. We found allocation of financial and human resources of single firms to be crucial for collaboration success. Collaboration in network organization was also found to be dependent on whether executives took part in the process, which increased the overall commitment to the project. Once compatibility of firms was reached through partner selection, for example the combination of complementary resources required by the task at hand, social dynamics within teams became more important. This reflects the 
more general discussion about economic and relational factors of inter-firm collaboration and collaborative capability [7, 10]. As Blau [15] states: "Social exchange relations evolve in a slow process, starting with minor transactions in which little trust is required because little risk is involved and in which both partners can prove their trustworthiness, enabling them to expand their relation and engage in major transactions. Thus, the process of social exchange leads to the trust required for it in a selfgoverning fashion." (p. 454).

Since the process of building collaborative capability comprises mutual adaptation of partners, it is rather slow and time consuming. Therefore our finding, that partners tended to repeatedly collaborate with one another once they shared a history of successful collaboration is not surprising. This kind of "nurturing" of existing relationships occurred in the KC network, too, resulting in more cohesive networks and in some cases in the establishment of virtual enterprises. Dyer and Singh [26] argue that such processes of establishing structural cohesion lead to coevolving capabilities. From their perspective, partners gain competitive advantage from inter-firm relationships by recombination of resources and capabilities at early stages of collaboration. Over time, partners' competences coevolve and may become indivisible.

Acknowledgments. This research is supported by the Swiss National Science Foundation (SNF) DORE grant 13DPD3-117972. The authors would like to thank the Swiss National Science Foundation for its support.

\section{References}

1. Tyler, B.B.: The Complementarity of Cooperative and Technological Competencies. A Resource-based perspective. Journal of English Technology Management 18, 1-27 (2001)

2. Schreiner, M., Corsten, D.: Integrating Perspectives: A Multidimensional Construct of Collaborative Capability. In: Beyerlein, M.M., Johnson, D.A., Beyerlein, S.T. (eds.) Complex collaboration: Building the capabilities for working across boundaries. JAI Press, Asterdam (2004)

3. Miles, R.E., Snow, C.C.: Organizations: New Concepts for New Forms. California Management Review 28, 62-73 (1986)

4. Miles, R.E., Snow, C.C.: Organizational Strategy, Structure, and Process. Stanford University Press, Stanford (2003)

5. Powell, W.W.: Neither market nor hierarchy: Network forms of organization. In: Staw, B.M., Cummings, L.L. (eds.) Research in organizational behavior. JAI Press, Greenwich (1990)

6. Sydow, J.: Management von Netzwerkorganisationen - Zum Stand der Forschung. In: Sydow, J. (ed.) Management von Netzwerkorganisationen. Gabler, Wiesbaden (2006)

7. Blomqvist, K., Levy, J.: Collaboration Capability - A Focal Concept in Collaborative Knowledge Creation And Innovation in Networks. International Journal of Management Concepts and Philosophy 2, 31-48 (2006)

8. Curall, S.C., Judge, T.A.: Measuring trust between organizational boundary persons. Organizational Behavior and Decision Processes 64, 151-170 (1995)

9. Cullen, J.B., Johnson, J.L., Sakano, T.: Success through commitment and trust: the soft side of strategic alliance management. Journal of World Business 35, 223-240 (2000) 
10. Heimeriks, K.H., Schreiner, M.: Alliance capability, collaboration quality, and alliance performance: an integrated framework. Eindhoven Center for Innovation Studies, Eindhoven (2002)

11. Niemelä, T.: Inter-Firm Co-Operation Capabilit. In: The Context Of Networking Family Firms: The Role Of Trust. Working paper, University of Jyväskylä (2003)

12. Sivadas, E., Dwyer, F.R.: An examination of organizational factors influencing new product success in internal and alliance-based processes. Journal of Marketing 1, 31-49 (2000)

13. Vartiainen, M., Kokko, N., Hakonen, M.: Competences in virtual organizations. In: Proceedings of the 3rd International Conference on Researching Work and Learning, pp. 209219. Universtiy of Tampere, Tampere (2003)

14. Mohr, J., Spekman, R.: Characteristics of partnership success: partnership attributes, communication behavior, and conflict resolutions techniques. Strategic Management Journal 15, 135-152 (1994)

15. Blau, P.M.: Interaction: Social exchange. In: Sills, D.L. (ed.) The international encyclopedia of the social sciences. The Free Press and Macmillan, New York (1968)

16. Lorenzoni, G., Lipparini, A.: The leveraging of interfirm relationships as a distinctive organizational capability: a longitudinal study. Strategic Management Journal 20, 317-338 (1999)

17. Kale, P., Dyer, J.H., Singh, H.: Alliance capability, stock market response, and long-term alliance success: the role of the alliance function. Strategic Management Journal 23, 747 767 (2002)

18. Anand, B.N., Khanna, T.: Do firms learn to create value? The case of alliances. Strategic Management Journal 21, 295-315 (2000)

19. Zucker, L.G., Darby, M.R., Brewer, M.B., Peng, Y.: Collaboration Structure and Information Dilemmas in Biotechnology: Organizational Boundaries as Trust Production. In: Kramer, R.M., Tyler, T.R. (eds.) Trust in Organizations - Frontiers of Theory and Research. Sage, Thousand Oaks (1995)

20. Bozeman, B., Corley, E.: Scientists' collaboration strategies: implications for scientific and technical human capital. Research Policy 33, 599-616 (2004)

21. Stokols, D., Harvey, R., Gress, J., Fuqua, J., Phillips, K.: In Vivo Studies of Transdisciplinary Scientific Collaboration. Lessons Learned and Implications for Active Living Research. American Journal of Preventive Medicine 28, 202-213 (2005)

22. Dosi, G., Nelson, R.R., Winter, S.G.: The Nature and Dynamics of Organizational Capabilities. Oxford University Press, Oxford (2000)

23. Sydow, J., Duschek, S., Möllering, G., Rometsch, M.: Kompetenzentwicklung in Netzwerken: eine typologische Studie. Westdeutscher Verlag, Wiesbaden (2003)

24. March, J.G.: Exploration and Exploitation in Organizational Learning. Organization Science 2, 71-87 (1991)

25. Lambe, C.J., Spekman, R.E., Hunt, S.D.: Alliance Competence, Resources, and Alliance Success: Conceptualization, Measurement, and Initial Test. Journal of the Academy of Marketing Science 30, 141-158 (2002)

26. Dyer, J.H., Singh, H.: The Relational View: Cooperative Strategy and Sources of Interorganizational Competitive Advantage. Academy of Management Review 23, 660-679 (1998) 